\title{
Progress in the Science and Technology of Gold
}

\section{Report on International Conference held in Hanau, Germany - 16-20 June 1996}

David Thompson

Consulting Chemist, Reading, England, UK

This meeting was attended by 170 participants drawn from 21 countries and five continents. Sessions centred around the theoretical chemistry of gold and a wide variety of academic and applications research areas. In addition to the oral presentations there were posters on a variety of topics.

\section{THEORETICAL CHEMISTRY OF GOLD}

Professor Pelkka Pyykkö (Department of Chemistry, University of Helsinki, Finland) set the stimulating tone with the first paper, entitled 'Theoretical Chemistry of Gold: New Species and the Auriophilic Attraction'. The relativistic effect provides an understanding of the unique position of gold in the family of elements. Electrons in atoms with high atomic numbers are influenced by the increased

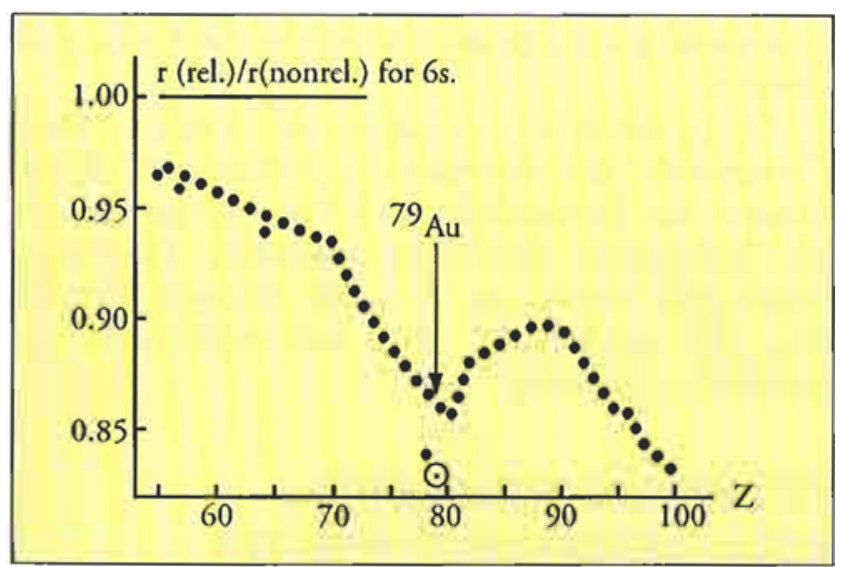

Figure 1 'Relativistic contraction' $\left(r_{n} / r_{\text {nown }}\right)$ for the 6 or orbitals of the heavy elements as a function of the atomic number $Z$. The element gold $(Z=79)$ represents $a$ pronounced local minimum (see reference 1). nuclear point charge and reach speeds which are approaching the velocity of light, and therefore must be treated according to Einstein's theory of relativity $(1,2)$. The 'relativistic contraction' for gold is illustrated in Figure 1. This relativistic effect consists of the following components:

- s-orbital and, to a smaller extent, p-orbital contraction

- $\quad$ spin orbit coupling, and

- f-orbital expansion

The unique yellow colour of gold derives from the relativistic effect. The Van der Waals interactions between gold atoms are correlation effects. Pyykkö had predicted gold-rare gas chemical bonds before a compound containing Au-Xe bonds had been prepared (2). The $\mathrm{Au}^{+}$ion is not noble in a classical sense - it is reactive, especially in the gas phase.

In his paper entitled 'Relativistic Effects in the Chemistry of Gold - An Overview', Professor Peter Schwerdtfeger (Department of Chemistry, University of Auckland, New Zealand) indicated the many apparent anomalies in the physical properties of gold compared with those of the other elements of Group 11 (IB) ie silver and copper, including colour, specific resistivity, electrical heat capacity, melting point and boiling point. Whereas the predominant oxidation states for copper are $\mathrm{Cu}(\mathrm{I})$ and $\mathrm{Cu}(\mathrm{II})$, and $\mathrm{Ag}(\mathrm{I})$ 
predominates for silver, $A u(I)$ and $A u(I I I)$ are the most stable for gold. There is good agreement between the various methods for calculating the relativistic bond contraction in $\mathrm{Au}_{2}$. Relativistic effects lead to increased Van der Waals interaction and increased physisorption energies on gold surfaces. In a recent paper (4), the structures of $\mathrm{AuX}_{3}$ and $\mathrm{Au}_{2} \mathrm{X}_{6}$ have been rationalized.

\section{CO-ORDINATION AND ORGANOMETALLIC CHEMISTRY OF GOLD}

Professor Alan Balch of the Department of Chemistry, University of California, Davis, USA, described a remarkable yellow luminescence displayed by gold complexes containing $\mathrm{Au}(\mathrm{I})-\mathrm{Au}(\mathrm{I})$ interactions. The structures contained knitted interwoven chains $(5,6)$. Contact with liquid triggers a faint yellow 'solvoluminescence' effect from the photoirradiated solid. The energy storage in $\mathrm{Au}_{3}(\mathrm{MeN}=\mathrm{COMe})_{3}$ derives from charge separation and charge mobility along columnar structures giving luminescence involving surface states. The solvent eats away at the surface, producing new surface. $\left[\mathrm{Au}_{3}(\mathrm{MeN}=\mathrm{COMe})_{3}\right]_{3} \mathrm{ClO}_{4}$ is obtained as orangebrown crystals and its behaviour has been characterized via cyclic voltammetry. This material is currently being evaluated for photoconductivity.

Professor Richard Puddephatt of the University of Western Ontario, Canada, talked about 'Rings, Chains and Polymers with Organogold Centers'. This chemistry is based on the 'linear' geometry of the gold compounds and intermolecular Au-Au interactions enable stacks of molecules to be produced. Professor Lyudmila Kuz'mina of the Institute of General and Inorganic Chemistry, Moscow, Russia described the structural chemistry of some monovalent gold compounds in which there were Van der Waals interactions between gold atoms $(7,8)$.

\section{SOLID STATE CHEMISTRY OF GOLD, LIQUID CRYSTALS AND GOLD CLUSTERS}

Professor Martin Jansen, Institut für Anorganische Chemie der Universität Bonn, Germany, described the synthesis of binary and ternary aurides and their electronic properties. Examples were $\mathrm{Na}_{2} \mathrm{LiAu}_{3}$, $\mathrm{M}_{3} \mathrm{AuO}(\mathrm{M}=\mathrm{K}, \mathrm{Rb}, \mathrm{Cs}), \mathrm{Cs}_{3} \mathrm{AuO}$, and $\mathrm{Rb}_{3} \mathrm{AuO}$, the last of which has metallic conductivity properties.
Some mixed copper oxides, e.g. $\mathrm{CuAu}_{2} \mathrm{O}_{4}$ are being investigated for evaluation as superconductors, but no yttrium has been introduced into these investigations, as yet.

Professor Peter Weinberger (Institut für Electrochemie der Technischen Universität Wien) described gold and related systems for applications in magnetoelectronics using the induced magnetic moment obtained for iron layers deposited onto gold layers. Formation of an alloy at the interface can change the anistropy. Professor Frederick Wagner (Physikdepartment der Technischen Universität Munchen, Germany) indicated the usefulness of gold Mössbauer spectroscopy in studying the chemistry and mineralogy of gold - it can be used to define the oxidation state, covalency, molecular symmetry, and in 'fingerprint' applications. Examples of definition of the mineralogy of gold, for identifying 'invisible gold', characterizing ruby catalysts (found to be gold (I)), and the analysis of gold coins (a non-destructive and depthselective technique) were described. Professor Graham Bowmaker (Department of Chemistry, University of Auckland, New Zealand) described vibrational and solid state NMR spectroscopy of gold complexed with strongly basic phosphine ligands.

In a talk entitled 'Is your Gold Bar Real? A Modern Method to Check', Dr C Henning (Degussa $A G$, Hanau) described the resonance frequency method and the DIGOR ${ }^{\mathrm{R}}$ test system. This is a rapid method intended for use on gold-dealing counters, and has been recently upgraded to enhance the ease of operation and reduce the time required for the test.

Professor Pablo Espinet (Facultada de Ciencias, Universidad de Vallodolid, Spain) described goldcontaining liquid crystals from mesogenic phases, in which gold plays a prominent role in the building of domains.

'The Electronic Structure of Gold Cluster Compounds' was described by Professor N Rösch (Institut für Physikalische und Theoretische Chemie der Technischen Universität Munchen, Germany). Naked gold clusters exist from $\mathrm{Au}_{2}$ through $\mathrm{Au}_{6}$, and $A u_{13}$ right up to $A u_{147} . A u_{55}$ was identified as the perfect electron model.

\section{CATALYTIC REACTIONS INVOLVING GOLD SPECIES}

Professor Günter Schmid of the Institut für Anorganische Chemie, Universität Essen, Germany has practical evidence for the importance of 55 atom 
clusters (particle diameter $1.4 \mathrm{~nm}$ ) and described the preparation of $\mathrm{Au}_{55} \mathrm{Cl}_{6}\left(\mathrm{PPh}_{3}\right)_{12}$. The isomerization of hexanes (2,2-dimethylbutane to $n$-hexane) was studied using $1 \% \mathrm{Au}_{55}$ on $\mathrm{TiO}_{2}$ (anatase). Au/Pd colloids, in which the gold is coated with palladium show enhanced catalytic activity for the hydrogenation of 2hexyne to 2-hexene, and palladium coated with gold is also active, even though pure gold is inactive. It may be possible to make wires of nanotechnology dimensions from these clusters (9).

Professor Louis Pignolet (Department of Chemistry, University of Minnesota, USA) talked about 'Catalytic Applications of Platinum- and Palladium-Gold Clusters'. The $\mathrm{H}_{2} / \mathrm{D}_{2}$ equilibrium was studied using $\left[\mathrm{Pt}\left(\mathrm{AuPPh}_{3}\right)_{8}\right]\left(\mathrm{NO}_{3}\right)_{2}$. There was a ratedetermining dissociation of $\mathrm{PPh}_{3}$. The clusters were then supported on alumina and silica and the $\mathrm{H}_{2} / \mathrm{D}_{2}$ equilibrium again studied. If activated at moderate temperatures, the cluster could be desorbed after catalysis. It was concluded that partial and reversible ligand desorption and/or cluster distortion takes place on the support giving rise to significant effects on activation. Treatment under hydrogen increases this effect. Magic Angle Spinning solid state NMR was used to characterize the surface species (10).

A significant development in catalysis, i.e. use of a gold compound as a homogeneous catalyst in solution was described by Professor Sanshiro Komiya of the Department of Applied Chemistry, Tokyo University of Agriculture and Technology, Japan. In this groundbreaking work, gold alkoxides having stable goldoxygen bonds were synthesized and used to catalyse the following Knoevenagel reaction $(11,12)$ :

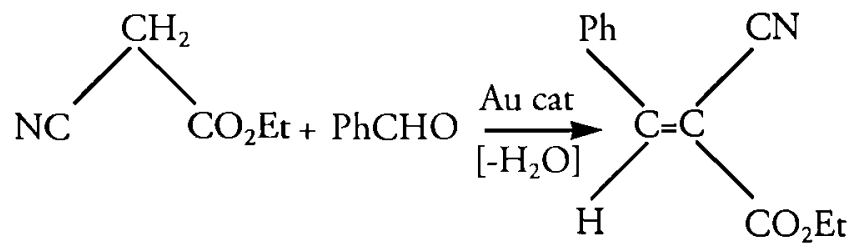

\section{GOLD MATERIALS}

Dr David Jacobson (GEC-Marconi, Hirst Division, Borehamwood, England, UK) presented an account of the work recently described in Gold Bulletin (13) on new gold alloys for low temperature soldering of high carat golds. A gold-germanium-silicon alloy system has been demonstrated to be capable of furnishing solders melting below $450^{\circ} \mathrm{C}$ for gold jewellery with a fineness in the range 21-23 carats. The application of a thin gold plating to alloys in foil form confers the requisite flow and spreading characteristics, when melted under a nitrogen atmosphere. Good colour matching can be achieved by a short post-soldering heat treatment, which modifies the alloy microstructure. The mechanical properties of these materials, as determined by shear and peel tests, are suitable for jewellery applications.

Yoshinobu Watanabe from Tanaka Kikinzoku International KK, Japan gave a talk entitled 'Progress in the Technology of Gold Powders and Gold Pastes' and, during the subsequent question time, indications of precipitation methods and gold leaf mechanical methods for preparing the gold powders were discussed. For use in printed circuits, the intriguing question is why does glass escape from gold at 700 $800^{\circ} \mathrm{C}$ and return to the gold at $900^{\circ} \mathrm{C}$ ?

Talks by Heraeus and Degussa staff gave authoritative pictures of major applications for gold. These were entitled 'Electroplating of Gold for Decorative Applications' (by Dr F Simon, Degussa AG, Schwäbisch Gmünd), 'Gold-Bonding Wires for Joining and Building-Up Technologies (Dr $\mathrm{H}$ Behrends (Heraeus GmbH, Hanau), and 'Gold for Decoration of Glass and Ceramics (Dr G Landgraf (Heraeus GmbH, Hanau). These talks clearly demonstrated the wide applications already achieved for gold in commercial products, and the sound technology underlying them.

\section{GOLD IN MEDICINE AND DENTISTRY}

Professor Peter Sadler (Birbeck College, London, UK) gave a stimulating and authoritative account of the usage of gold systems in past and current medical applications, including the important use of Auranofin (Ridaura ${ }^{\mathrm{TM}}$ ) for the treatment of rheumatoid arthritis $(14,15)$.

This was followed by a stimulating paper from $\mathrm{Dr}$ Sue Berners-Price (School of Science, Griffith University, Nathan, Australia) who described very demanding synthetic work which is leading to compounds with effects in cancer screens. The work is centred on the synthesis and evaluation of watersoluble gold(I) complexes of bidentate pyridylphosphines, following earlier work investigating $\left[\mathrm{Au}_{2}(\mu \text {-dppe })\right]^{2+}$ systems $(16,17)$. Dr C Frank Shaw, Department of Chemistry, The University of Wisconsin, Milwaukee, USA) described 'Redox and Ligand-exchange Reactions of Gold (I)-Based Drugs'. 
Talks from Dr Wulf Brämer (Heraeus-Kulzer $\mathrm{GmbH}$, Hanau) entitled 'Gold in Dentistry' and $\mathrm{Dr}$ Josef Rothaut and Dr Bernd Kempf (Degussa AG Hanau) on 'Modern Trends and Developments in Precious Metal Dental Alloys' and 'Thermodynamic Modelling of the Precipitation Hardening in Gold Alloys' respectively clearly demonstrated the importance of this field and its sophisticated stage of technology development. Professor S Hisatsune (School of Dentistry, Nagasaki University, Japan) described the work of Professor Katsuhiro Yasuda et al on 'Microstructural Changes Induced by Phase Transformations in Dental Alloys'.

\section{PROSPECTING FOR AND REFINING GOLD}

Professors David Groves (Department of Geology, University of Western Australia, Nedlands) and Jeffrey Hedenquist (Geological Survey of Japan) gave two very well presented talks on the methods used to define areas of high prospectivity for gold. Experience gained from studies on volcanoes and hot springs which are currently active are proving to be very useful in providing insight into where gold might have accumulated in the past.

Hydrothermal processing is used to recover gold from deep seams. The gold is transported in the form of a reduced sulphur complex $\mathrm{Au}(\mathrm{SH})_{2}{ }^{-}$, and can be precipitated by wall rock sulfidation:

$$
\mathrm{Au}(\mathrm{SH})_{2}^{-}+1 / 2 \mathrm{H}_{2} \rightarrow \mathrm{Au}^{0}+\mathrm{H}_{2} \mathrm{~S}+\mathrm{SH}^{-}
$$

Concentrations of gold can therefore be present at the well head.

Professor Peter Möller (Geo-Forschungszentrum, Potsdam, Germany) talked about the electrochemical accumulation of visible gold on sulfide minerals in nature and related these processes to n-type and p-type processes in oxide semiconductors. Ubiquitous pn junctions in fractured sulfide minerals act as electrorefiners for gold.

Dr Mike Adams (Mintek, Johannesburg, South Africa) described 'Recent Developments in the Chemistry of Gold Recovery, Processing and Environmental Impact'. He included descriptions of bacterial leaching, alternative lixiviants for gold, resin in pulp processing, cyanide removal procedures, and in situ gold refining for 9999 and 99999 high purity golds, and gave pointers for the future, including underground processing.
Dr Jürgen Lorösch (Degussa AG, Hanau) described chloride leaching processes for the recovery of gold. A number of 'safe' cyanide processes are well developed. Alternative processes are also being investigated. These include those based on bioleaching, thiourea, thiosulfate, or halogen leaching, e.g.:

$$
\begin{gathered}
2 \mathrm{Au}+\mathrm{Cl}_{2} \rightarrow 2 \mathrm{AuCl} \\
2 \mathrm{AuCl}+6 \mathrm{Cl}^{-} \rightarrow 2 \mathrm{AuCl}_{4}^{-} \\
2 \mathrm{Au}^{-} \mathrm{Cl}_{2}+6 \mathrm{Cl}^{-} \rightarrow 2 \mathrm{AuCl}_{4}^{3-}
\end{gathered}
$$

A 'New Process for Gold Extraction from Refractory Ores' was described by Dr Frank Letowski (School of Process and Materials Engineering, University of Witwatersrand, Johannesburg, South Africa). This process is based on the chloride leaching of gold and PGM from ores, concentrates and tailings and has been developed to a large laboratory scale. Gold and platinum group metals are efficiently recovered from the leach solution via absorption on carbon, and the process has environmental advantages.

An overview of the methods currently available for gold refining and recycling was given by Dr Wolfgang Dähne (Kronberg, Germany), and Dr Hans-Martin Lüschow (Degussa AG, Hanau) gave a detailed account of the methods currently used and being developed for the analysis of gold in a precious metals refinery.

\section{HISTORY OF GOLD IN JEWELLERY AND COINAGE}

At an evening session of public lectures chaired by Professor Schmidbaur, there were talks on "The Early Metallurgy of Gold' by Professor H G Bachmann (Hanau), and on 'Celtic Coins: Facts and Fakes' by Professor W. Stern of the University of Basel. It is clear that advanced knowledge on methods for effectively working gold and its alloys has been available from the days of early civilisations.

\section{POSTERS}

Posters were presented relevant to most of the plenary sessions of the conference and provided further points for the initiation of stimulating discussions amongst the participants. A few only of the fifty posters presented can be selected here for comment.

New aspects of gold carbene chemistry were described by Stephanie Cronje, Helgard G Raubenheimer, Mieke Desmet, Louise Lindeque, 
Pierre J Oliver and Gert J Kruger, Rand Afrikaans University, Auckland Park, South Africa. Lithiated azolyl and thienyl precursors which undergo transmetallation with gold can be protonated or alkylated to give carbene complexes.

Complexes of ketimine with the coinage metals are relevant for the partial oxidation of ammonia and amines to give hydrazines; and $\mathrm{Ph}_{2} \mathrm{C}=\mathrm{NH}$ complexes of $\mathrm{Cu}(\mathrm{I}), \mathrm{Ag}(\mathrm{I})$ and $\mathrm{Au}(\mathrm{I})$ have been prepared and structurally characterized by Wolfgang Schneider, Andreas Bauer and Hubert Schmidbaur of the Anorganisches-chemisches Institut der Technischen Universität München, Germany.

The synthesis, characterization and luminescence studies on $\mathrm{Na}_{8}\left[\mathrm{Au}(\mathrm{TPPTS})_{3}\right]$ (TPPTS = trisodium tris( $m$-sufonatophenyl)phosphine) were described by Zerihun Assefa, John P Fackler, Jennifer M Forward and Tiffany A Grant of Texas A\&M University, USA. This compound exhibits luminescence in aqueous solution.

The possibility of gold being used as a substitute for copper in high temperature superconductors has led Claudia Figulla, Martina Ralle, Jutta Geb and Martin Jansen of the Institut für Anorganische Chemie der Universität Bonn to synthesize $\mathrm{La}_{4} \mathrm{Au}_{2} \mathrm{O}_{9}, \mathrm{Nd}_{4} \mathrm{Au}_{2} \mathrm{O}_{9}$ and $\mathrm{Bi}_{4} \mathrm{Au}_{2} \mathrm{O}_{9}$ from $\mathrm{Au}_{2} \mathrm{O}_{3} \cdot 2 \mathrm{H}_{2} \mathrm{O}$ and $\mathrm{L}_{2} \mathrm{O}_{3-}(\mathrm{La}=\mathrm{La}$, $\mathrm{Nd}, \mathrm{Bi}$ ) using hydrothermal conditions under high pressures of oxygen. The structural relations of these three compounds to $\mathrm{Bi}_{2} \mathrm{CuO}_{4}$ was discussed.

The liquid crystal behaviour of linear $\left[\mathrm{AuX}\left(\mathrm{C}=\mathrm{NC}_{6} \mathrm{H}_{4} \mathrm{OC}_{11} \mathrm{H}_{21+1}\right)\right](\mathrm{X}=$ halogen $)$ can be tuned by changing the nature and structure of the ligands. Rocio Bayon, Mohamed Benouazzane, Silverio Coco, Pablo Espinet, Jose Martin-Alvarez and Cesar FernandezMayordomo of the Universidad de Valladolid, Spain described the effects of changing isonitrile substituents and halogens on the mesogenic properties.

Two examples were given of recent research projects carried out at the Forschungsinstitut für Edelmetalle und Metallchemie, Schwäbisch Gmünd, Germany. The poster by Hermann A Jehn, Dieter Ott and Andreas Zielonka described techniques for investment casting of jewellery and improved wear resistance with electroplated gold dispersion layers.

There were two posters describing $\mathrm{Au} / \mathrm{Cu}$ based alloys, presented by a team from Kyushu University, Fukuoka, Japan. Riichi Ouchida, Takanobu Shiraishi, Masahara Nagakawa, Shigeki Matsuya and Michio Ohta described factors affecting the age-hardening rate, using hardness testing, differential thermal analysis, and theoretical calculations of internal energy changes associated with order-disorder transformation. Shape change associated with order-disorder transformation was studied using a thin sheet of equiatomic $\mathrm{AuCu}$ and $\mathrm{AuCu}-\mathrm{Ga}$ alloys - when the external stress was applied during ordering heat treatment, a given shape was obtained, and by disordering, the specimen completely regained its original shape ('shape memory' effect).

\section{CONCLUSIONS}

The meeting was notable for its broad coverage of the various aspects of the science and technology of gold, and its lively multidisciplinary discussions after talks and around the 50 poster presentations. There is considerable scope for developments, especially in the chemistry and the homogeneous and heterogeneous catalysis of gold, as well as in the areas of solid state effects (e.g. luminescence and high temperature superconductivity), and medical applications. Some new aspects of gold metallurgy were reported and these are likely to find use in the jewellery and dental applications areas. Theoretical work provides a rationale for the uniqueness of gold and justification for further exploration of applications for new chemistry and metallurgy.

The conference was very well organized by Professor $\mathrm{H}$ Schmidbaur and his staff from the Technical University of Munich and by Professor $\mathrm{H}$ Offermanns as the co-Chairman with his associates at Degussa together with representatives of Heraeus. The administration was handled efficiently by the German Chemical Society (GDCh). The generous sponsorship by Degussa and Heraeus was complemented by support from the City of Hanau, the local Chamber of Commerce, the German Science Foundation, the European Science Foundation (REHE Programme), and the World Gold Council. Participation should have stimulated many thoughts on new avenues for scientific exploration and industrial applications using gold and its derivatives, and this in turn will continue to stimulate new and improved methods for locating and refining gold. It is to be hoped that this excellent conference will form a basis for future meetings designed to follow progress in the expanding area of gold science and technology. It is a pity that there are to be no published conference proceedings but we look forward to seeing many of the interesting papers published in Gold Bulletin or elsewhere.

\section{ACKNOWLEDGEMENT}

The author is grateful to Dr Annette Schier of the Technical University of Munich for reading the 
manuscript for this report and making a number of useful suggestions for modifications.

\section{REFERENCES}

1 H. Schmidbaur, Gold Bull., 1990, 23, 11

2 P. Pyykkö, Chem. Rev., 1988, 88, 563

3 P. Pyykkö J. Amer. Chem. Soc., 1995, 117, 2067

4 P. Schwerdtfeger, Angew. Chem., 1996, 108, 2973

5 A.L. Balch, E.Y. Fung and M.M. Olmstead, $J$. Am. Chem. Soc., 1990, 112, 5181

6 P.M. Van Calcar, M.M. Olmstead and A.L. Balch, J. Chem. Soc., Chem. Comm., 1995, 1773

7 Yu. T. Struchkov, Yu.L. Slovokhotov, D.N. Kratsov, T.V. Baukova, E.G. Perevalova and K.J. Gandberg, J. Organomet. Chem., 1988, 338, 269

8 J.P. Fackler, R.J. Staples, A. Elduque and T. Grant, Acta Cryst. C, 1994, 50, 520.
9 G.M. Francis and R.E. Palmer, Gold Bull., 1996, 29, 47

10 D.T. Thompson, Gold Bull., 1996, 29, 70

11 S.-I. Murahashi, T. Naota, H. Taki, M. Mizuno, H.Takaya, S. Komiya, Y.Mizuho, N. Oyasato, M. Hiraoka, M. Hirano and A. Fukuoka, J. Am. Chem. Soc., 1995, 117, 12436

12 Y. Mizuhu, N. Kasuga and S. Komiya, Chem Letters, 1991, 2127

13 D.M. Jacobson and S.P.S. Sangha, Gold Bull., $1996,29,3$

14 S.L. Best and P.J. Sadler, Gold Bull., 1996, 29,

15 S. Fricker, Gold Bull., 1996, 29, 53

16 S.J. Berners-Price, P.S. Jarrett and P.J. Sadler, Inorg. Chem., 1987, 26, 3074

17 C.K. Mirabelli, D.T. Hill, L.F. Faucette, F.L. McCabe, G.R. Girard, D.B. Bryan, B.M. Sutton, J.O'L. Bartus, S.T. Crooke and R.K. Johnson, J. Med. Chem., 1987, 30, 2181.

\section{A L E N D A R}

\section{IPMI Catalysis Seminar}

The International Precious Metals Institute (IPMI) has arranged a Catalysis Seminar in Houston, Texas, USA from October 21 st23rd 1996.

The Seminar Programme will consist of four sessions entitled 'Homogeneous Catalysis', 'Selective Heterogeneous Catalysis', 'New Direction in PGM Catalysis' and 'Petroleum Processing'.

Other meetings planned by IPMI include a Recovery/Refining Seminar in Las Vegas, Nevada from 27-29 January 1997, and an Environmental Seminar in Arlington, Virginia from 25-27 February 1997. For further information contact International Precious Metals Institute, 4905 West Tilghman Street, Suite 160, Allentown, Pennsylvania 181094-9137, USA. Tel. +16103959700

$F a x+16103955855$

\section{International Conference on Gold Mining in the CIS}

The Adam Smith Institure is organizing a conference on The Mining and Processing of "Gold and Diamonds in the CIS', to be held on 27-28 November 1996 at Le Meridien hotel in London.

This high level conference will tackle the major questions facing the industry today and provide an updated appraisal of investment, operational and technical issues in the gold and diamond industries of the CIS. Highlights include investment and operational case studies and an afternoon of round table discussions providing the opportunity to discuss issues specific to each area with top government and industry representatives from the principal gold and diamond producing regions of the CIS (Including the Russian Far East and Central Asian Republics).
For further information please contact Christina Raeburn at the Adam Smith Institute, 11-13 Charterhouse Buildings, London, ECIM $7 A N$, England $U K$. $\mathrm{Tel}+44$ (171) 4903774

Fax $+44(171) 4902362$

The Editor would be pleased to receive for publication any information on events, conferences or meetings associated with gold science, technology and its applications. 